\title{
DEPURACIÓN ALTERNATIVA, CON APORTE TÉRMICO DE ENERGÍA SOLAR
}

\author{
Antoni Martínez-Taberner, Víctor Martínez-Moll, \\ Gabriel Moyà Niell, Andreu Moyà Salom y Caterina Amengual Morro \\ Facultat de Ciències \\ Universitat de les Illes Balears
}

\section{RESUMEN}

La situación del Campus de la UIB, aislado de la ciudad, ligado al tema de la escasez del agua ha permitido el desarrollo de un sistema de depuración in situ de las aguas residuales producidas en las propias instalaciones universitarias. El proceso se desarrolla íntegramente con sistemas de depuración natural en un diseño que combina 3 tecnologías existentes: el lagunaje, los humedales construidos y los filtros verdes arbolados.

La innovación se produce en un sistema de regulación térmica del lagunaje para evitar la inversión térmica, que provoca situaciones puntuales de malos olores. Se trata de aprovechar el calor residual de una instalación de climatización solar en un edificio cercano a la laguna, de tal manera que la laguna ejerza de refrigerador del sistema y a la vez aproveche el calor para potenciar la estratificación térmica.

Palabras clave: Sistemas de depuración natural, lagunaje, energía solar térmica, estratificación térmica

\section{SUMMARY}

The location of the Balearic Islands' University Campus, isolated from the city of Palma, has made possible the construction of an on-site wastewater treatment plant to remedy the scarcity of water. The plant runs with natural wastewater systems mixing three well known technologies: waste stabilization ponds, constructed wetlands and tree filters.

The innovation in this field is done by a thermal regulation to avoid the destratification events that causes bad odours in the main pond. It involves taking advantage of the residual heat of solar air-conditioning facilities installed in a nearby building. The residual heat is used to increase the stratification on the pond to avoid the thermal destratification.

Key words: Natural wastewater treatment, waste stabilization ponds, thermal solar energy, thermal stratification 


\section{Objetivo}

La finalidad del presente proyecto es obtener, partiendo de una entrada de aguas residuales, unas salidas del sistema de depuración en forma de aguas regeneradas y compost. Para ello diseñamos tres fases de depuración complementarias, con aporte extra de energía solar térmica para el control y aceleración de procesos metabólicos.

Este proyecto experimental debe demostrar la posibilidad de obtener la multifuncionalidad del parque garantizando la eliminación de olores fétidos y la presencia de mosquitos, la actividad depurativa del periodo de invierno y la calidad del diseño paisajístico.

La aplicación de estos sistemas resulta particularmente eficiente para eliminar la sobrecarga estival de muchas depuradoras convencionales situadas en zonas turísticas, lo cual evita su redimensionamiento; así mismo resulta útil en núcleos rurales, urbanizaciones, parques tecnológicos e industriales y en general lugares en donde resulta ineficiente el sistema tradicional, ya sea por excesivo bombeo o por caudales insuficientes, los cuales no justifican grandes inversiones. Finalmente cabe recordar el interés de muchos municipios, particularmente turísticos, en esponjar el tejido urbano y complementar sus parques y jardines, lo cual puede hacerse con este tipo de intervenciones.

\section{Bases de partida con las que se inicia el proyecto}

\section{Recursos territoriales e infraestructura funcional invertidos en el proyecto}

Para la realización del proyecto demostrativo se dispone de una parcela rectangular de $68382 \mathrm{~m}^{2}$ situada en la zona central del Campus que corresponde a la zona de menor cota (entre 78 y $85 \mathrm{~m}$ ), su nombre es el de Prat de la Font de la Vila. Esta zona está contemplada como zona de esparcimiento en el Plan Especial de Ordenación del Campus de la UIB.

En esta zona se han incorporado dos lagunas impermeables de depuración vertical, se ha adecuado el perfil topográfico de una buena parte de la parcela y se ha hecho una intervención con la siembra de un centenar de árboles que actúan de filtro de dendrodepuración.

Las lagunas están dimensionadas para tratar los $112 \mathrm{~m}^{3} /$ día que son los que se obtienen de media en el Campus de la UIB. La primera laguna alcanza un volumen de $2278 \mathrm{~m}^{3}$ y una superficie de $2128 \mathrm{~m}^{2}$ aunque solo tiene $1799 \mathrm{~m}^{2}$ de aguas libres debido a la incorporación de un pequeño islote central, su profundidad media es de $1,27 \mathrm{~m}$ y la máxima de $2,5 \mathrm{~m}$, este volumen ofrece un tiempo de residencia del agua en la laguna de 20 días. La segunda laguna, a una cota de un metro por debajo de la primera tiene un carácter de reserva y de aireación, tienen $916 \mathrm{~m}^{3}$ de capacidad, con las mismas características que la anterior y un tiempo de residencia del agua de 8 días. 
Descripción del proceso

\section{depuración alternativa}

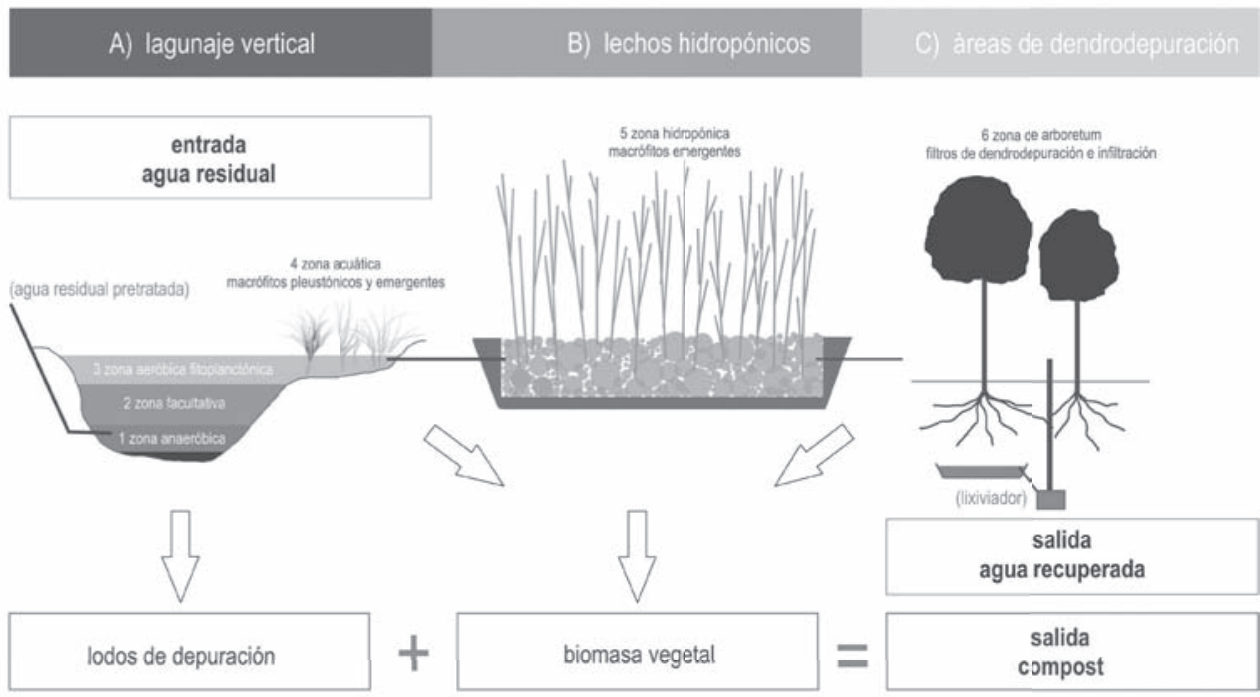

ค1 UิB Universitat de les

IIles Balears

A) Fase. Lagunaje vertical con Infraestructura de aporte calórico.

Se realiza una sola laguna profunda y meromíctica, en la que pueden diferenciarse 4 subzonas. Muchos sistemas de depuración utilizan lagunas de poca profundidad $(0,6$ a 1 m) con 3 o 4 compartimentos o lagunas en horizontal. Sin embargo, para evitar el exceso de evaporación, y consecuente concentración de sales en el agua residual, resulta más adecuado un sistema vertical, el cual además incorpora menos materia orgánica fotosintética en el proceso, debido a su menor exposición a la luz.

Las 4 zonas que diferenciamos en la laguna de desarrollo vertical instalada en el Campus equivalen a los compartimentos o lagunajes horizontales y son las siguientes:

1. Zona anaeróbica. Es la zona profunda de la laguna, entre 2,7 y $1 \mathrm{~m}$ de profundidad. En esta zona se libera el agua residual que previamente ha sido tamizada para eliminar sólidos. En esta zona se producen fermentaciones que empiezan a fraccionar las macromoléculas orgánicas que se encuentran en los residuos del agua. La función principal es la de sedimentación de sólidos en suspensión y fermentación bacteriana.

2. Zona facultativa. Es una zona intermedia y oscilante, entre 1,8 y $0,5 \mathrm{~m}$ de profundidad. En esta zona puede haber unas ciertas cantidades de oxígeno de forma intermitente y es el lugar en donde oscila la quemoclina. La función de esta zona es de tampón y de contribución parcial a la fermentación y la fotosíntesis. 
3. Zona aeróbica. Es la zona superficial, entre un metro y la superficie. En esta zona existe intercambio con la atmósfera y actividad fotosintética con liberación de oxígeno. En esta zona empezamos los procesos de oxidación y estabilización de la materia orgánica, en ella se debe garantizar la presencia de oxígeno y la supervivencia de peces como Gambussia affinis y ciprínidos para eliminar las larvas de mosquitos. La función de esta zona es la de incorporar oxígeno a la masa superficial del agua mediante fotosíntesis y contacto con la atmósfera y crear una barrera de oxidación de los gases susceptibles de liberares des de la masa anóxica.

4. Zona de macrofitos pleustónicos. Corresponde a la zona litoral de la parte aeróbica y superficial de la laguna. En esta zona y gracias a los macrófitos flotantes empezamos a incorporar nutrientes del agua a biomasa activa que puede recogerse a medida que las plantas van creciendo y utilizarse para el compostaje posterior. El jacinto de agua (Eichornia crassipes) junto con la lenteja de agua (Lemna sp.) son dos especies complementarias que se utilizan corrientemente como pleustónicas de depuración. La función de esta zona es la de empezar un proceso de absorción de nutrientes por incorporación a biomasa activa.

5. Infraestructura control de la temperatura. Corresponde al sistema encargado de controlar que la temperatura en los distintos estratos de la laguna se mantenga dentro de unos niveles idóneos en función de las condiciones climáticas exteriores y de los requerimientos del proceso de depuración. Esta infraestructura de gestión de la temperatura es innovadora y se deben hacer las pruebas necesarias para su correcto dimensionamiento. Sus funciones son básicas para el funcionamiento óptimo de la laguna y para la credibilidad de la multifuncionalidad el sistema. Estas funciones son las siguientes:

a. La principal función del sistema térmico será garantizar la inexistencia de mezclas verticales del agua o desestratificaciones, las cuales producen el afloramiento de agua anóxica con la consiguiente liberación de gases fétidos y mortalidad de los peces que controlan la proliferación de las larvas de mosquitos que se desarrollan en la superficie.

b. Adicionalmente el sistema de aporte calórico permitirá acelerar y mantener la actividad microbiana, tanto fermentativa como fotosintética en niveles cercanos a los óptimos, evitando las desaceleraciones y las paradas invernales.

Para la realización de las funciones de control, se prevén diversos subsistemas. El más importante de éstos es el Sistema de Aportación de Calor Solar en la Zona Aeróbica, el cual está formado básicamente por un campo de captadores solares de baja temperatura, un deposito de acumulación y un sistema de intercambio de calor que permita la transferencia de la energía captada a la capa más superficial de la laguna (primeros 0,5 m), este sistema seria el encargado, tanto de mantener la temperatura en los niveles óptimos como de evitar las desestratificaciones. Un segundo subsistema consiste en el Sistema de Evacuación de Calor en la Zona Anaeróbica, este subsistema funcionaria únicamente como mecanismo de reserva para evitar las desestratificaciones por lo que únicamente entraría en funcionamiento cuando el sistema de aporte de calor no pudiera garantizar un perfil de temperaturas idóneo, es decir en momentos en que la temperatura ambiente sea claramente inferior a la del agua de la laguna, esto permite realizar la evacuación de calor mediante simples intercambiadores aire-agua, sin necesidad de aporte adicional de energía. Finalmente, en caso de que los dos sistemas anteriores no fuesen capaces de realizar por si solos la función de control que se proyecta, se contempla la posibilidad de implantar un sistema de aislamiento térmico superficial o manta térmica desplegable, la 
cual sólo se aplicaría de forma temporal en los momentos en que las pérdidas de calor fuesen máximas ya que este sistema interfiere en cierta medida con la las funciones de la laguna como espacio de recreo. Esta situación es altamente improbable en la Isla de Mallorca debido a que las situaciones de heladas, siempre débiles oscila entre 3 o 4 al año en la zona demostrativa.

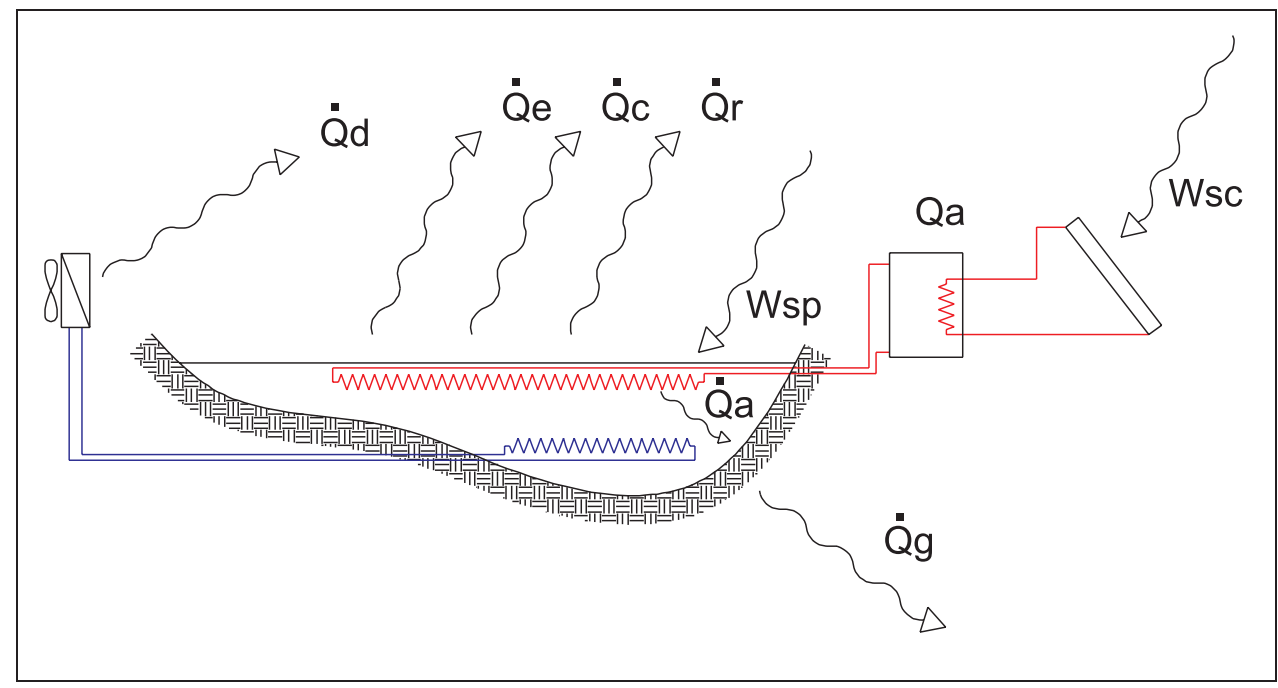

Leyenda:

Qr energía disipada por radiación

Qc energía disipada por convección

Qe energía disipada por evaporación

Qa energía almacenada en el acumulador

Wsc radiación solar interceptada por los captadores solares

Wsp radiacinón solar incidente sobre la laguna

Qd calor disipado por los intercambiadores aire-agua

\section{Disipación Calor residual}

A parte del sistema solar directo, se aprovecharán los mismos equipos de aporte calórico para hacer un sistema solar indirecto, con aporte de calor residual de los sistemas de climatización de los edificios de la Universidad. Se realizará mediante colectores solares de media temperatura utilizados para procesos de climatización de edificios, en el que sólo se utilizará el calor residual para la laguna, teniendo un efecto doble, el de regulación de la temperatura de la laguna y el de ahorro energético en el edificio a climatizar. Este segundo proceso a su vez contribuye a disminuir las emisiones de $\mathrm{CO}_{2}$. Para un equipo frigorífico convencional aire-agua comparando con un sistema agua-agua, el efecto invernadero directo es siete veces menor, y si tenemos en cuenta que la eficiencia puede llegar a ser bastante mayor, el efecto invernadero global es sensiblemente menor. Este sistema ya se esta aplicando en otros procesos y se realizará conjuntamente con el equipo 
de Ingeniería de la construcción y gestión energética para aplicaciones en los edificios de la Universidad de las Islas Baleares y otras aplicaciones para el sector turístico. La gran ventaja de este sistema es que va a permitir con los mismos equipos, un ahorro energético en los edificios de al universidad y una regulación de la temperatura de la laguna de depuración durante todo el año, evitando las desestratificaciones y acelerando el proceso metabólico.
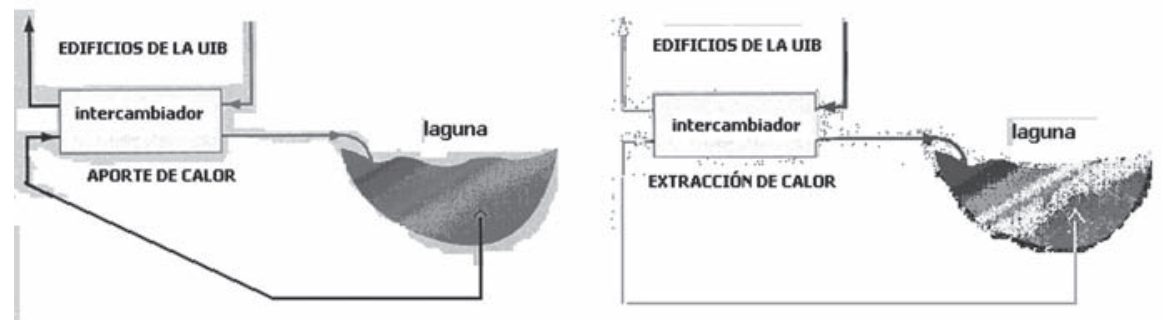

Esquema de disipación/extracción de calor residual a través de un acuífero

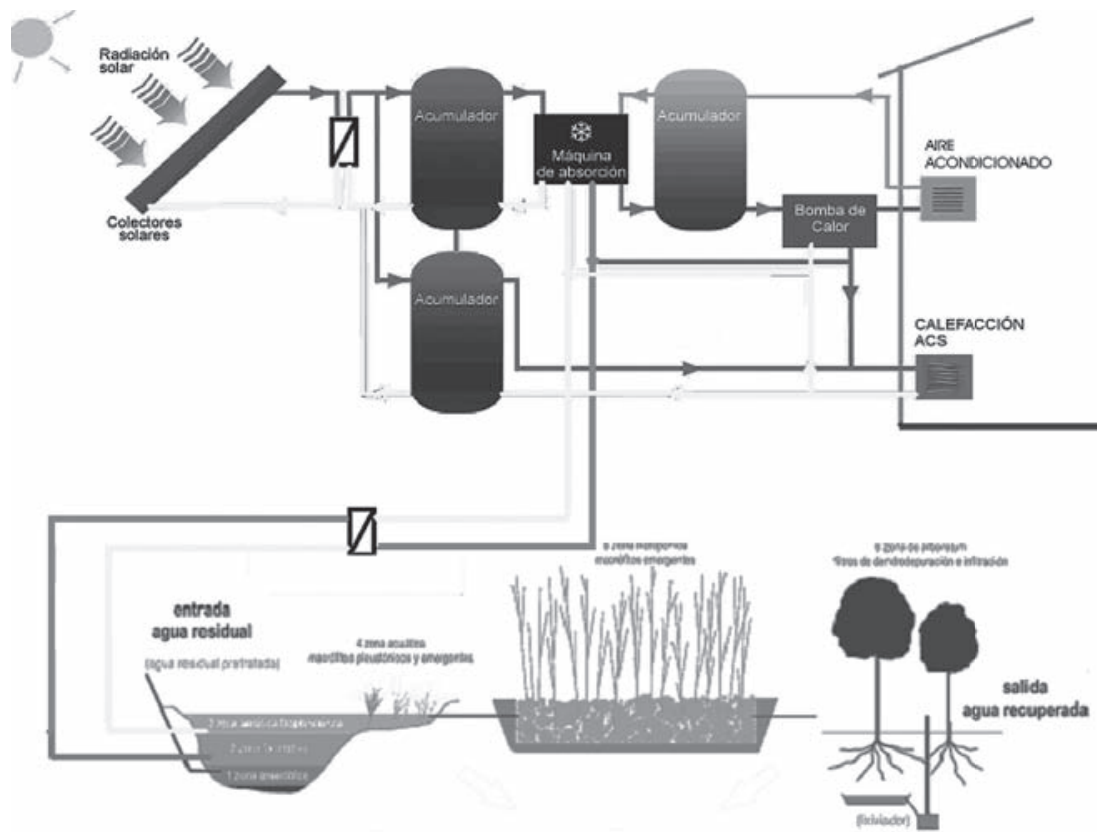

Esquema de Climatización Solar y apoyo de calor residual a la depuración de la laguna

La realización de esta parte tendrá también su carga pedagógica debido a que permitirá hacer practicas y ser utilizado como proyecto demostrativo para la aplicación de estas tecnologías en otros campos y procesos, todo ello sin necesidad de un gasto energético significativo ni una contribución al Cambio Climático. 


\section{B) Fase. Lechos hidropónicos}

Esta fase incluye la creación de un lecho impermeable para el cultivo hidropónico de plantas emergentes de máxima producción primaria. El objetivo es la incorporación de nutrientes del agua para formar biomasa y la retención de la materia orgánica que no ha quedado retenida en el sistema de lagunaje vertical. Estos lechos son altamente eficientes en la deseutrofización del agua, en la eliminación de la demanda química de oxígeno, en la eliminación de bacterias fecales y en la retención de sólidos en suspensión.

El diseño del lecho debe optimizarse para facilitar la siega anual o bianual de las plantas, de manera que el sistema esté, siempre que se a posible, en el máximo nivel de producción primaria. Las especies y su proporción serán objeto de estudio para la optimación de su compostaje con los lodos de depuración obtenidos en el lagunaje.

Las especies de carrizo (Phragmites australis), enea (Thypha latifolia) y sesquera (Cladium mariscus) presentan características morfológicas y de composición química muy interesantes para ser utilizadas como substrato acompañante de los lodos de depuración.

La función de esta fase es la de retener en el suelo hidropónico la materia orgánica que no ha sedimentado en las lagunas y de completar la absorción de nutrientes por incorporación a biomasa activa fácil de recolectar.

\section{C) Fase. Filtros de dendrodepuración e infiltración}

En esta fase se han seleccionado especies leñosas con alta capacidad para asimilar aguas residuales y actuar de último filtro verde. Estas especies deben estructurarse en diseños adecuados paisajísticamente para un uso recreativo y deben llevar algunos sistemas dispersos de recogida de lixiviados para el control de la calidad del agua que finalmente se libera al acuífero.

La actividad de las plantas leñosas como deseutrofizadoras es poco significativa en comparación con los lechos hidropónicos pero son necesarias para dar el sentido de multifuncionalidad al parque, para la infiltración del agua y para la eliminación de patógenos del agua que se da en el proceso de infiltración del agua.

Corrientemente se utilizan choperas (Populus alba) para esta función pero en estudios realizados por el grupo de investigación y gracias a la financiación de la CAICyT hemos obtenido resultados óptimos para esta función con otras especies como la adelfa (Nerium oleander) y altas eficiencias en otras leñosas de tipo arbóreo, lo cual nos permite diversificar los filtros verdes de dendrodepuración y facilitar los diseños de los parques de depuración.

La función de los filtros de dendrodepuración es la de favorecer la infiltración del agua a través del complejo suelo-raíces provocando la eliminación de bacterias fecales y patógenos, servir de control de salida del agua del sistema y proporcionar un valor añadido al conjunto paisajístico. La liberación del agua y recarga del acuífero es el punto final del proceso que da el sentido de sostenibilidad devolviendo el residuo en forma de recurso a los ciclos biogeoquímicos naturales.

\section{Bibliografía}

CLADERA. P., MESTRE, I., MARTÍNEZ-TABERnER, A. (2001): Disseny per a un parc de depuració terciaria. Parc a Santanyi. III Jornades del Medi Ambient de les Illes Balears. Palma de Mallorca. 
DUFFIE, J.A. y BECKMAN, W.A. (1991): Solar engineering of thermal processes. Wiley \& Sons, Inc. 919 pp.

FERMORE, T.R. (1993): «Applied aspects of composting and bioconversion of lignocellulosic materials: an overview». International Biodeterioration \& Biodegradation 31, 87-106.

FIKSEL, J. (1997) Ingeniería del Diseño Medioambiental. DFE. McGraw-Hill. 511 pp.

HAMMER, D.A. (1992) Creating Freshwater Wetlands. Lewis Publishers, CRC Press. 298 pp.

JESSEN, B.L., PICCHIONI, G.A., \& MEXAL, J.G. (1999) Total biomass and ion accumulation of Eucalyptus camaludensis, hibrid Populus, and Robinia pseudoacacia irrigated with saline municipal wastewater. HortScience 34(3), 491-492.

KENT, D.M. (1994) Applied Wetland Science and Technology. Lewis Publishers, CRC Press. $436 \mathrm{pp}$.

MOSHIRI, G.A. (1993): Constructed Wetlands for Water Quality Improvement. Lewis Publishers, CRC Press. 632 pp.

MOYÀ, G., MARÍNEZ-TABERNER, A., ADROVER, M., VADELL, J., RAMÓN, J. Y RAMÓN, G. (2002): Experimental Dendrodepuration. First Results. In: Tecnologías de pequeña escala para la Depuración y Gestión de Aguas Residuales en el Ámbito Mediterráneo. Sevilla.

RAMON, J., SÁNCHEZ-FORSS, A., VADELL, V., MARTÍNEZ-TABERNER, A. (2001): La dendrodepuración como alternativa en el ciclo de depuración de aguas residuales.2001.- V Jornadas Técnicas de la Sociedad Española de Agricultura Ecológica. Mallorca.

SALGOT, M, SÁNCHEZ, X. \& TORRENS, A. (1999): Recursos d'aigua. Fundación Agbar. 448 pp.

SEOÁNEZ, M. (1999): Aguas residuales: tratamiento por humedales artificiales. Fundamentos científicos. Tecnologías. Diseño. Ediciones Mundi Prensa. Madrid 326- pp. 